\title{
A generic simulation model for prediction of thermal conditions and human performance in cockpits
}

J örg Schminder and Roland Gårdhagen

The self-archived postprint version of this journal article is available at Linköping University Institutional Repository (DiVA):

http:// urn.kb.se/ resolve?urn=urn:nbn:se:liu:diva-152069

N.B.: When citing this work, cite the original publication.

Schminder, J ., Gårdhagen, R., (2018), A generic simulation model for prediction of thermal conditions and human performance in cockpits, Building and Environment, 143, 120-129.

https:// doi.org/ 10.1016/j.buildenv.2018.06.055

Original publication available at:

https://doi.org/10.1016/j.buildenv.2018.06.055

Copyright: Elsevier

http:// www.elsevier.com/

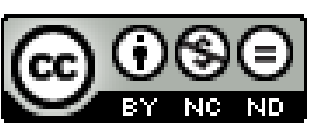




\title{
A Generic Simulation Model for Prediction of Thermal Conditions and Human Performance in Cockpits
}

\author{
Jörg Schminder ${ }^{1}$, Roland Gårdhagen \\ Linköping University, Department of Management and Engineering, Sweden
}

\begin{abstract}
This paper presents a computational approach to predict the thermal environment in a cockpit during on-ground and in-flight aircraft operation. A method was developed to model cockpit air temperature, which serves as input to black-globe and wet-bulb temperature computation. Subsequently the simulated temperatures are used to compute common heat stress indices such as Wet Bulb Globe Temperature (WBGT), Fighter Index of Thermal Stress (FITS), or Predicted Mean Vote (PMV). To demonstrate the manifold information made available by the computed heat stress indices, WBGT e.g. is set in relation to different types of occupational exposure limits demonstrating not only the possibility to predict physiological constraints but mental performance too. The generic cockpit model and thermal comfort computations were validated against experimental data gained from on ground temperature measurements inside an aircraft cockpit, which underwent a sudden large temperature change. The results exemplify how thermal comfort and possible physical as well as mental degradation of aircrews can be assessed quickly using the presented model.
\end{abstract}

Keywords: Thermal comfort, Heat stress, Mental performance, Simulation

\footnotetext{
${ }^{1}$ Corresponding author.

E-mail address: jorg.schminder@liu.se (J.Schminder).
} 


\section{Introduction}

Operating helicopters, fighters, and light aircraft on ground or at low altitudes means, especially during hot summer weather, heavy thermal loads on the occupants and on the aircraft systems. These are caused by high outside air temperature (OAT) and solar radiation through the large window. The risk of thermal fatigue thereby rises significantly with time both for humans and for electric components [1], [2], [3].

In the future, heat-related problems will exacerbate. Electric mobility is globally considered as an important key to achieve the goal of emission free passenger transport [4], [5], [6], which also affects the aviation industry [7], 8]. However, shifting to more-electrical or all-electrical aircraft causes manifold problems which have to be overcome. One major challenge with replacing mechanical parts with electrical parts is the increased amount of waste energy (heat), which has a direct effect on the overall efficiency of the aircraft and thus its range. Compensating the range problem with an increasing amount of lightweight composite materials with low thermal conductivity adds, together with reduced/removed thermal sinks (fuel), the problem of rejecting

heat energy [9], [10]. Maintaining current performance and preventing heatrelated system failures and occupants' thermal discomfort will be a challenge. This calls for innovative thermal simulation tools to enable risk predictions and optimization of future technical solutions. 


\subsection{Heat Stress Assessment}

The American Society of Heating, Refrigerating and Air-Conditioning Engineers (ASHRAE) defines thermal comfort as: "the condition of mind that expresses satisfaction with the thermal environment, which is assessed by subjective evaluation" [11]. Human's individual thermal comfort ratings are diverse. Differences in the human physiology, age, the culturally determined plurality of human thermal expectations, and a variety of clothing are only some reasons why it is very challenging to predict thermal comfort [12], [13], [14], [15]. However, thermal comfort indices can provide general guidance for what conditions comfort are most likely experienced by a certain group of people [16], [17]. A limitation with the, to date, almost 40 presented indices is that none of them can be applied universally to estimate thermal comfort on an individual level in all different kinds of thermal studies. In addition, there is also the difficulty of comparing the indices with each other as well as sorting them.

Epstein [18] suggests sorting heat stress indices into three groups: indices that are based on calculations involving heat balance equations (rational indices), indices that are based on objective and subjective strain (empirical indices), and indices based on direct measurements of environmental variables (direct indices). He also states that indices, which demand a large amount of physiological and environmental in-data for their computation (needed for rational and empirical indices) are more comprehensive but for practical reasons are less popular. He therefore suggests the use of direct indices. 


\subsection{Indicators of Thermal Comfort and Performance}

The Effective Temperature (ET) indicates the corresponding temperature sensation felt by an occupant in his/her present situation compared to a notional environment in which the air is still and saturated. Since the original ET does not consider the important effect of radiation on the occupants' experience of thermal comfort, a later version (Vernon [19]) called the Corrected Effective Temperature (CET) is applied in this work. In addition, Bedford [20], [21] developed two nomograms for CET taking the effect of clothing insulation for 0.5 clo and 1 clo into account; these are computed using Eq. (1) and Eq. (2).

$$
\begin{gathered}
C E T_{0.5 c l o}=\frac{\left(0.944 T_{d b}-0.056 T_{p w b}\right)}{1+0.022\left(T_{d b}-T_{p w b}\right)} \\
C E T_{1 c l o}=\frac{\left(1.21 T_{d b}-0.21 T_{p w b}\right)}{1+0.029\left(T_{d b}-T_{p w b}\right)}
\end{gathered}
$$

The Wet Bulb Globe Temperature (WBGT) is to date one of the most frequently used and discussed heat stress indices and has quite often served as a blueprint for other thermal comfort related indicators. The virtue of WBGT is its simplicity and that the index responds to some of the most important parameters influencing thermal comfort, namely radiation, evaporation, and convection in a physically similar way to the human body. This is achieved by combining and balancing black globe temperature $T_{b g}$ (considering radial

effects) with natural wet bulb temperature $T_{n w b}$ (representing the ease of 
evaporation, i.e. sweating, depending on humidity), and the surrounding dry air temperature $T_{d b}$. WBGT is defined as [22]:

$$
W B G T=0.7 T_{n w b}+0.2 T_{b g}+0.1 T_{d b}
$$

There are two fundamentally different approaches to predict WBGT. Several studies [23], 24], 25] suggest an empirical approach, making accurate, extensive and costly WBGT measurements necessary. Alternatively, a pure computer based simulation approach, such as that presented by Liljegren [26] and Gaspar [27], can be applied to model WBGT in various environments.

WBGT alone has little explanatory power of thermal comfort if not related to any type of human sensual and/or mental restrictions. However, a universal WBGT related heat limit threshold, covering all diverse personal and environmental aspects, is impossible to set. ISO 7243 [22] gives WBGT reference values, which have been established to monitor heat strain on workers (men and women) in hot environments depending on their acclimatization level and physical activity, Table 1. The workers' activity level is not defined by a specific work task but generally expressed in metabolic rate. The clothing insulation in ISO 7243 considers a person wearing a T-shirt together with light trousers (0.6 clo).

High metabolic demands caused by physical strain are rather uncommon un- 


\section{Table 1}

ISO 7243 22]: WBGT occupational exposure limits for a person with a clothing insulation of 0.6 clo.

\begin{tabular}{lcc}
\hline Metabolic rate & \multicolumn{2}{c}{ WBGT reference value } \\
\cline { 2 - 3 }$\left(W m^{-2}\right)$ & Acclimatized $\left({ }^{\circ} \mathrm{C}\right)$ & Not acclimatized $\left({ }^{\circ} \mathrm{C}\right)$ \\
\hline Resting $M<65$ & 33 & 32 \\
$65<M<130$ & 30 & 29 \\
$130<M<200$ & 28 & 26 \\
$200<M<260$ & 25 & 22 \\
$M>260$ & 23 & 16 \\
\hline
\end{tabular}

der normal flight conditions but can occur for example during flights with high g-loads. In contrast, high mental loads due to multiple information processing tasks are more likely to be observed at low metabolic rates. Hancock [28] developed cognitive performance limits during heat stress based on ET, which he transformed into WBGT scale values. Eq. (4) describes the general form of these performance limits. Parameter $a$ defines the empirical intercept of the limit lines with the thermal intensity axis, see Table $2, b$ is the constant slope for each task category curve $(b=-5.435)$, and $t_{e x}$ is the exposure time.

$$
W B G T_{\text {limit }}=a-b \log _{e}\left(t_{e x}\right)
$$

Each of these mental performance limits represents the loss of a certain attentional ability. A favorable characteristic of Hancock's limits is that they consider the time a human is exposed to hot environmental conditions and 
Table 2

Empirical and tolerant adjusted WBGT limits interception values for each performance line [28].

\begin{tabular}{lcc}
\hline & \multicolumn{2}{c}{ Tolerance adjusted } \\
Task type & Empirical intercept $\left({ }^{\circ} \mathrm{C}\right)$ & intercept $\left({ }^{\circ} \mathrm{C}\right)$ \\
\hline Vigilance performance & 48.02 & 46.0 \\
Dual-task performance & 55.68 & 54.0 \\
Tracking performance & 63.11 & 62.5 \\
Simple mental performance & 65.33 & 64.0 \\
Physiological tolerance & 66.56 & 65.0 \\
\hline
\end{tabular}

necessary cooling remedies can thus be better deduced.

One adaption of WBGT is the Fighter Index of Thermal Stress (FITS) [29]. It was developed as a tool to support aircrews' assessment of and decisionmaking on hazardous heat stress risks in single- or two-seat fighter aircraft. The pilots' insulation is between 1.5 clo and 2 clo, and the index combines onground measured psychometric wet bulb $T_{p w b}$ and dry bulb $T_{d b}$ temperature as

$$
F I T S=0.8281 T_{p w b}+0.3549 T_{d b}+5.08^{\circ} \mathrm{C}
$$

To interpret FITS results, Stibley and Nunneley [29] suggested two risk levels: a caution zone $\left(\right.$ FITS $=32^{\circ} \mathrm{C}-38^{\circ} \mathrm{C}$ ) in which aircrews should be alert that a decrease in their physiological and mental performance can occur, and a danger zone $\left(\right.$ FITS $>38^{\circ} \mathrm{C}$ ) in which the risk of suffering dehydration and 
heat stroke from insufficient thermoregulation is severe. They recommended that ground operation and flights at low altitude on clear or moderately overcast days when dangerous FITS values are reached should be avoided or postponed.

The Predicted Mean Vote (PMV) is essentially the thermal comfort response of a large number of people to different thermal environments whose rating led to a mathematical model relating the results to both physical factors like air temperature, mean radiant temperature, air speed, and humidity and subject-specific parameters like metabolic rate and clothing [17. In contrast to ET, PMV does not refer to a temperature but to a seven-step scale from Cold (-3) to Hot (+3). PMV is computed using Eq. (6), where $M$ represents the occupant's individual rate of metabolic heat production and $L$ the thermal load on his/her body [30].

$$
P M V=\left(0.303 e^{-0.036 \cdot M}+0.028\right) L
$$

Alternatively, PMV can be determined according to Eq. (7) in terms of dry air temperature and vapor pressure $e_{w}$ and empirically obtained tabulated values. The coefficients $\beta_{1}$ to $\beta_{3}$ depend on gender and exposure time [30], see Table 3 .

$$
P M V=\beta_{1} T_{d b}+\beta_{2} e_{w}+\beta_{3}
$$




\section{Table 3}

The coefficients $\beta_{1}, \beta_{2}$, and $\beta_{3}$ of ASHRAEs empirical PMV model for different exposure times and subject sex [30].

\begin{tabular}{llccc}
\hline Period & Occupants & $\beta_{1}$ & $\beta_{2}$ & $\beta_{3}$ \\
\hline \multirow{2}{*}{ h } & Men & 0.220 & 0.233 & -6.673 \\
& Woman & 0.272 & 0.248 & -7.245 \\
\multirow{3}{*}{$2 \mathrm{~h}$} & Both & 0.245 & 0.248 & -6.475 \\
& Men & 0.221 & 0.270 & -6.024 \\
& Woman & 0.283 & 0.210 & -7.694 \\
$3 \mathrm{~h}$ & Both & 0.252 & 0.240 & -6.859 \\
& Men & 0.212 & 0.293 & -5.949 \\
& Woman & 0.275 & 0.255 & -8.622 \\
& Both & 0.243 & 0.278 & -6.802 \\
\hline
\end{tabular}

PPD predicts the percentage of people who are likely to be dissatisfied at each PMV. It is a function of PMV and can be calculated as 30]

$$
P P D=100-95 e^{-\left(0.03353 P M V^{4}+0.2179 P M V^{2}\right)}
$$

The Predicted Percentage of Dissatisfaction (PPD) is the fraction of people that can be expected to be dissatisfied with the present thermal conditions [17]. It moves within a range of $0-100 \%$; $0 \%$ represents a neutral response of the occupants and $100 \%$ a significant dissatisfaction. Since it is very unlikely that all occupants respond with equal satisfaction to a certain thermal environment, ASHRAE 55 recommends a range of $10 \%$ as acceptable for indoor spaces.

While WBGT and FITS are indices to evaluate thermal discomfort in ex- 
tremely warm environments, ET, PMV, and PPD are indices validated for near-comfort conditions. In addition, ET, PMV, and PPD are all based on subjective evaluations to try to reflect the level of strain felt by a human in a certain thermal environment, whereas WBGT and FITS approach thermal comfort evaluation more objectively.

\subsection{Aim}

While measured heat stress parameters directly or indirectly facilitate quantification of past and instantaneous thermal comfort, simulation-based heat stress indices enable assessment and prediction of future trends, thus making the latter suitable for many different applications such as vehicle and aircraft design, medical treatments, planning of rescue missions, etc. In addition, the possibility of computing thermal comfort allows the user to prognosticate potentially dangerous or even life threatening situations in a fast and, through suitable visualization, self-explanatory way.

The objective of this work is to present a tool to assess thermal comfort in an aircraft cockpit based on simulated thermal in-data. The purpose is to provide a program that both offers the possibility to model the thermodynamic properties and processes inside the cockpit and facilitates thermal risk prediction on the occupants using well-established heat stress indices like ET, WBGT, PMV, and the FITS. Furthermore, the models are intended to be 
quick, generic, and compatible with other (external) models that enable high flexibility and optimization.

\section{Methods}

The presented compartment model is a combination of sub-models (Fig. 1 and Fig. 21 to compute the thermal conditions of the cockpit air, which can be used for estimation of the thermal comfort for the occupants. The different sub-models are explained in more detail in the following sections.

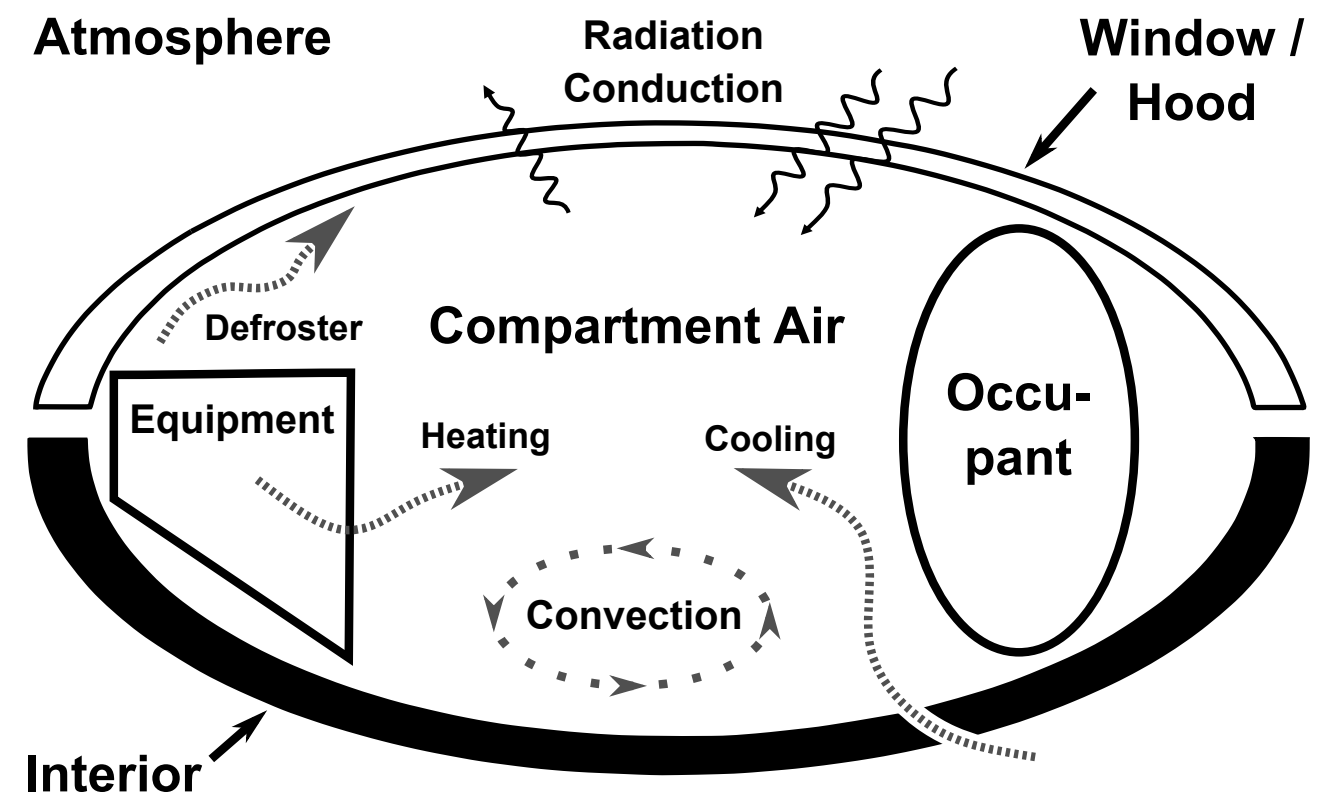

Fig. 1. The figure illustrates the presented compartment model, its sub-models (Atmosphere, Hood, and Interior), ventilation, and basic heat transfer interactions required to model compartment air temperature. 


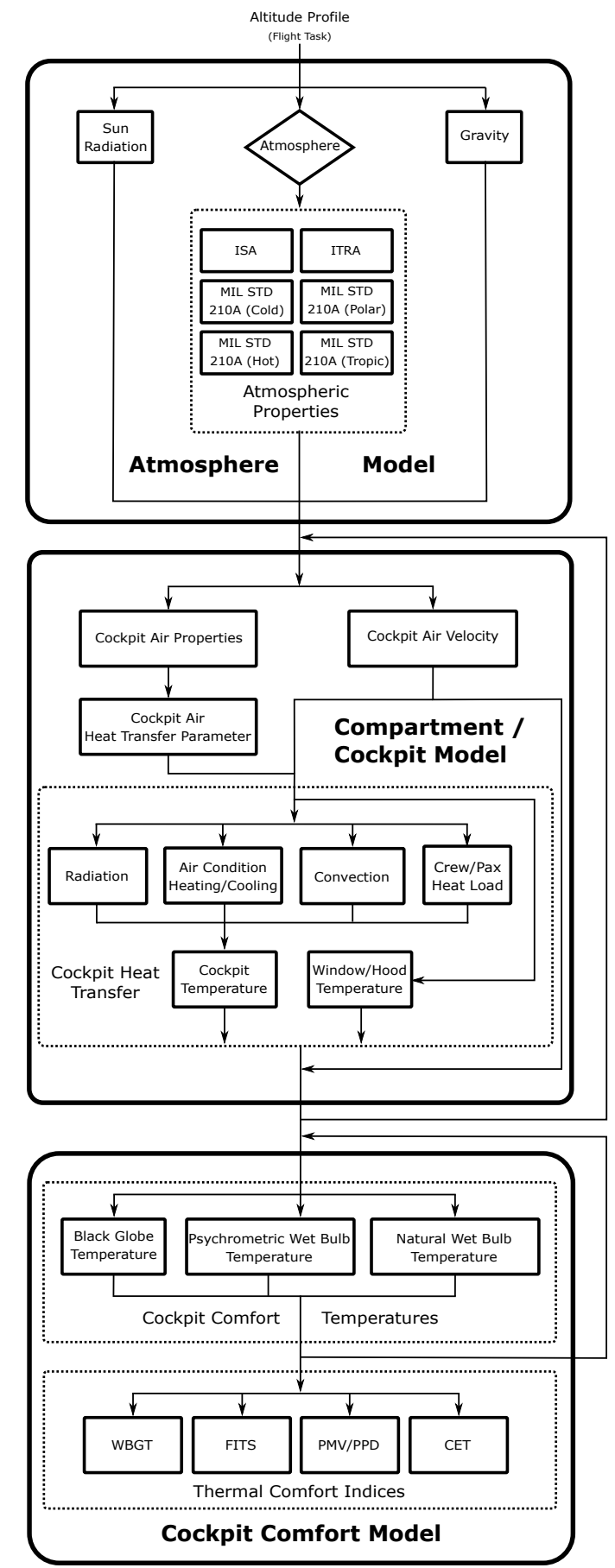

Fig. 2. Flow chart of the cockpit temperature and thermal comfort indices computation. 


\subsection{Atmospheric Boundary Conditions}

Atmospheric boundary conditions can be provided to all sub-models either by direct measurements, offered for example by the local meteorological office, or by choosing a generalized atmospheric model. Three atmospheric representations are implemented: the International Standard Atmosphere (ISA), the International Tropical Reference Atmosphere (ITRA), and the Military Standard MIL-STD-210. The International Standard Atmosphere, defined by ISO [31], is a model describing the changes in the following atmospheric properties: pressure, temperature, density, and viscosity. ISA often works in temperature regions around the mid-northern latitudes with moderate solar activity. Since atmospheric boundary conditions differ with season, place, and altitude, more regionally adapted reference models can increase their accuracy. The International Tropical Reference Atmosphere, suggested by Ananthasaynam and Narasimha in 1985 [32], can be used as an alternative in tropical regions. For more extreme climate conditions in the northern hemisphere, extreme cold or hot days, military standard MIL-STD-210 [33] can be selected.

\subsection{Occupant compartment model}

The compartment model consists of three major parts: the cockpit air, the interior, and the window/hood. The air and interior are modeled as onedimensional homogeneous lumped systems with uniform properties. The hood is also considered one-dimensional, but modeled using a finite differ- 
ence approximation. These models will be described in further detail in the following sections.

\subsubsection{Compartment air and interior model}

The compartment air model calculates the temporal variation in temperature inside the vehicle using Eq. (9) and Eq. (10) considering the heat flux to and from the compartment air volume plus additional heating or cooling due to occupants $\dot{Q}_{\text {occu }}$, equipment $\dot{Q}_{\text {equip }}$, air-conditioning $\dot{Q}_{v e n t}$, and deicing $\dot{Q}_{\text {def }}$ systems.

$$
\dot{Q}_{c}=\dot{Q}_{w_{c o n v}}+\dot{Q}_{i n t_{c o n v}}+\varsigma_{\text {equip } 1} \dot{Q}_{\text {equip }}+\dot{Q}_{\text {occu }}+\dot{Q}_{v e n t}+\dot{Q}_{d e f}
$$

$\dot{Q}_{w_{\text {conv }}}$ and $\dot{Q}_{\text {int }_{\text {conv }}}$ are the convective heat exchanges between the compartment air and the surfaces of the interior and window/hood, respectively. Time advancement of the compartment air temperature $T_{c}$, for a time step size $d t$, is achieved according to Eq. (10).

$$
T_{c}^{t+d t}=T_{c}^{t}+\dot{Q}_{c} \frac{d t}{m_{a i r} c_{p_{a i r}}}
$$

The variables $m_{\text {air }}$ and $c_{p_{a i r}}$ represent the total mass of the compartment air and its specific heat at constant pressure, respectively.

The same approach was chosen to compute the temperature of the cockpit interior. Eq. (11) shows the energy balance for the interior considering

radiation from all other radiating surfaces $\dot{Q}_{\text {int }_{\text {rad }}}$, the share of extra heat 
coming from the electrical equipment $\dot{Q}_{\text {equip }}$, the losses due to convection $\dot{Q}_{\text {int }_{\text {conv }}}$ and internal cooling $\dot{Q}_{\text {cool }}$. The parameters $\varsigma_{\text {equip } 1}$ in Eq. (9) and $\varsigma_{\text {equip } 2}$ in Eq. 11) are the shares of $\dot{Q}_{\text {equip }}$, which are absorbed by the interior or directly transferred to the cockpit air.

$$
\dot{Q}_{i n t}=\dot{Q}_{i n t_{\text {rad }}}+\varsigma_{\text {equip } 2} \dot{Q}_{\text {equip }}-\dot{Q}_{\text {int }}{ }_{\text {conv }}-\dot{Q}_{\text {cool }}
$$

The interior temperature $T_{\text {int }}$ is advanced in time in analogy to $T_{c}$, Eq. (12). The variables $m_{i n t}$ and $c_{p_{i n t}}$ represent the interior mass and its specific heat at constant pressure, respectively.

$$
T_{i n t}^{t+d t}=T_{i n t}^{t}+\dot{Q}_{i n t} \frac{d t}{m_{\text {int }} c_{p_{i n t}}}
$$

Apart from the temperatures, the model also determines the pressure inside the occupant compartment. In light aircraft the pressure normally changes with atmospheric air pressure at different altitudes, in contrast to more advanced aircraft like fighters or passenger aircraft, which are usually equipped with a pressurized cabin. If such a system is installed and has to be considered in the simulations, the model follows predefined pressure drop profiles, which depend on the type of aircraft.

\subsubsection{Window/Hood model}

The heat transfer to and through the window/hood is computed using a one-dimensional explicit finite difference approach, presented in Eq. (13) (15). The equations include the different heat transfer mechanisms occurring 
in each node of the window beginning at the outside and finishing at the inside. Radiation received from the outdoor environment and interior of the compartment is absorbed at the outer nodes of the window while sun radiation is distributed to all nodes. The share of sun radiation received by each node is represented by $\varsigma_{\text {sun }}$ Eq. (16) - (18). Convection, outdoor caused by wind and indoor due to ventilation, only occurs at the two outer nodes (Eq. (13) and Eq. (15)). The two convective heat transfer coefficients, $h_{w o}$ outside and $h_{w i}$ inside, are determined based on flow over a flat plate.

$$
\begin{gathered}
\frac{d T}{d t}=\frac{h_{w o}}{\rho_{w} c_{p_{w}} d x}\left(T_{\text {stag }}-T_{w}(1)\right)-\frac{k_{w}}{\rho_{w} c_{p_{w}} d x^{2}}\left(T_{w}(1)-T_{w}(2)\right)+\frac{\dot{Q}_{w o r}}{\rho_{w} c_{p_{w}} d} \\
\frac{d T}{d t}=k_{w} \frac{T_{w}(i-1)-2 T_{w}(i)+T_{w}(i+1)}{\rho_{w} c_{p_{w}} d x^{2}}+\frac{\dot{Q}_{w r}}{d \rho_{w} c_{p_{w}}}
\end{gathered}
$$

$$
\frac{d T}{d t}=\frac{k_{w}}{\rho_{w} c_{p_{w}} d x^{2}}\left(T_{w}(n-1)-T_{w}(n)\right)-\frac{h_{w i}}{\rho_{w} c_{p_{w}} d x}\left(T_{w}(n)-T_{c}\right)+\frac{\dot{Q}_{w i r}}{\rho_{w} c_{p_{w}} d}
$$

$T_{\text {stag }}$ is the stagnation temperature at the outside of the window, $T_{w}(i)$ the temperature of node $i, k_{w}$ the thermal conductivity of the window, $\rho_{w}$ the density of the window, $c_{p_{w}}$ the specific heat of the window, $d$ the thickness of the window, and $d x$ the node distance. The terms $\dot{Q}_{w o r}$ and $\dot{Q}_{w i r}$ represent the net amount of radiation to and from each of the two surface nodes 
computed using Eq. (16) and Eq. (18), respectively. In addition, due to the transparency, radiative heat transfer to the inside nodes $\dot{Q}_{w r}$ is considered, see Eq. (16).

$$
\begin{gathered}
\dot{Q}_{w o r}=\frac{\varsigma_{\text {sun }}}{n} \dot{Q}_{\text {sun }}+\sigma \epsilon_{w}\left(T_{a}^{4}-T_{w}^{4}\right) \\
\dot{Q}_{w r}=\frac{\varsigma_{\text {sun }}}{n} \dot{Q}_{\text {sun }} \\
\dot{Q}_{\text {wir }}=\frac{\varsigma_{\text {sun }}}{n} \dot{Q}_{\text {sun }}+\sigma \epsilon_{w}\left(T_{\text {int }}^{4}-T_{w}^{4}\right)
\end{gathered}
$$

In Eq. (16) - (18) $n$ is the number of nodes, $\sigma$ the Stefan Boltzmann constant, and $\epsilon_{w}$ the emissivity of the window. Ambient temperature $T_{a}$ and sun radiation $\dot{Q}_{\text {sun }}$ are provided by the atmospheric model.

\subsection{Simulating thermal comfort}

The considered thermal comfort and performance indicators are indices computed using dry air temperature (here $T_{c}$ ), black globe temperature, and wet bulb temperature. To model black globe Eq. (19) and wet bulb temperature Eq. (20), heat balance equations were developed.

$$
\dot{Q}_{b g}=\dot{Q}_{b g_{r a d}}+\dot{Q}_{b g_{c o n v}}
$$




$$
\dot{Q}_{w b}=\dot{Q}_{w b_{r a d}}+\dot{Q}_{w b_{c o n v}}-\dot{Q}_{w b_{e v a p}}
$$

The thermometers are affected by radiation, convection, and in the case of wet bulb also evaporation. Both thermometers exchange radiative energy $\dot{Q}_{\text {rad }}$ with the window as well as the interior and receive, to a certain percentage $\chi$, heat directly from the sun $\dot{Q}_{\text {sun }}$, see Eq. 21) and Eq. 222. The radiation of the black globe, wet bulb, window, and interior is determined by their body temperatures: $T_{b g}, T_{w b}, T_{w}, T_{i n t}$ (which are uniform throughout the material, except the window), their emissivities: $\epsilon_{b g}, \epsilon_{w b}, \epsilon_{w}, \epsilon_{i n t}$, and the Stefan Boltzmann constant $\sigma$.

$$
\begin{array}{r}
\dot{Q}_{b g_{\text {rad }}}=\alpha_{b g} A_{b g} \epsilon_{\text {hood }} \sigma\left(T_{w}^{4}-T_{b g}^{t 4}\right)+\beta_{b g} A_{b g} \epsilon_{i n t} \sigma\left(T_{i n t}^{4}-T_{b g}^{t 4}\right) \\
+\chi_{b g} A_{b g} \Psi_{\text {sun }} \dot{Q}_{\text {sun }} \\
\dot{Q}_{w b_{\text {rad }}}=\alpha_{w b} A_{w b} \epsilon_{h o o d} \sigma\left(T_{w}^{4}-T_{w b}^{t 4}\right)+\beta_{w b} A_{w b} \epsilon_{i n t} \sigma\left(T_{\text {int }}^{4}-T_{w b}^{t 4}\right) \\
+\chi_{w b} A_{w b} \Psi_{\text {sun }} \dot{Q}_{\text {sun }}
\end{array}
$$

Heat is also exchanged between the thermometers and the circulating cockpit air. This is assumed to occur both as forced (ventilation) and as natural convection, Eq. (23) - (24). The convective heat transfer coefficient for the black globe $h_{b g}$ was computed for a sphere placed in laminar or turbulent 
flow whereas the heat transfer coefficients for the wet bulb thermometer $h_{b g}$ was estimated from a vertical cylinder under the same flow conditions. Furthermore, $T_{c}$ in Eq. 23 - 24 is received as an input from the compartment model providing dry air temperature for both black globe and wet bulb temperature computations.

$$
\dot{Q}_{b g_{\text {conv }}}=A_{b g} h_{b g}\left(T_{b g}-T_{c}\right)
$$

$$
\dot{Q}_{w b_{c o n v}}=A_{w b} h_{w b}\left(T_{w b}-T_{c}\right)
$$

The additional evaporative losses at the wet bulb thermometer are presented in Eq. (25). The modeling approach is in analogy to Liljegreen [26].

$$
\dot{Q}_{\text {evap }}=\left(\frac{A_{w b} q_{e v H 2 O} h_{w b}}{c_{p_{\text {mair }}}}\right)\left(\frac{M_{H 2 O}}{M_{a i r}}\right)\left(\frac{P r}{S c}\right)^{0.56}\left(\frac{e_{w}-e_{c}}{P-e_{w}}\right)
$$

In Eq. (25) $q_{\text {evH2O }}$ is the heat of vaporization, $c p_{\text {mair }}$ the specific heat of the moist air at constant pressure, $M_{H 2 O}$ and $M_{\text {air }}$ the molecular weight of water vapor and air, respectively, $\operatorname{Pr}$ the Prandtl number, $S c$ the Schmidt number, and $P$ the compartment pressure. The vapor pressure at the surface of the wet bulb $e_{w}$ and vapor pressure of the air surrounding the wet bulb $e_{c}$ are 
computed as in 34.

The black globe area $A_{w b}$ corresponds to a standard black globe sphere of $150 \mathrm{~mm}$ in diameter whereas the wet bulb area $A_{w b}$ is the curved surface of a small cylinder of $7 \mathrm{~mm}$ in diameter and $25.4 \mathrm{~mm}$ in length. While convection and evaporation take place on the entire surface of the thermometers, radiation only occurs partially due to the partial exposure to the interior, diverse sun radiation, and shades. Hence the factors $\alpha, \beta$, and $\chi$ are the fractions of the area exposed to radiation.

$T_{b g}$ and $T_{w b}$ are advanced in time as presented in Eq. (26) and Eq. (27).

$$
\begin{gathered}
T_{b g}^{t+d t}=T_{b g}^{t}+\dot{Q}_{b g} \frac{d t}{m_{b g} c_{p_{b g}}} \\
T_{w b}^{t+d t}=T_{w b}^{t}+\dot{Q}_{w b} \frac{d t}{m_{w b} c_{p_{w b}}}
\end{gathered}
$$

\subsection{Experimental setup}

For validation, dry air, black globe, and wet bulb temperature were measured inside a light aircraft of Scottish Aviation Bulldog type (Swedish Air Force abbreviation SK 61) (Fig. 3) and compared to simulated data. In order to validate the steady state and dynamic behavior of the model the experiment was designed to include a sudden large temperature change. For this purpose the aircraft was, at the beginning of the test, placed inside a 
closed, dark hangar, followed by a period of direct exposure to sun radiation at an outside ramp position. Then it was moved back into the closed hangar, and measurements were stopped when cockpit air temperature approached a value close to what was measured at the beginning of the test.

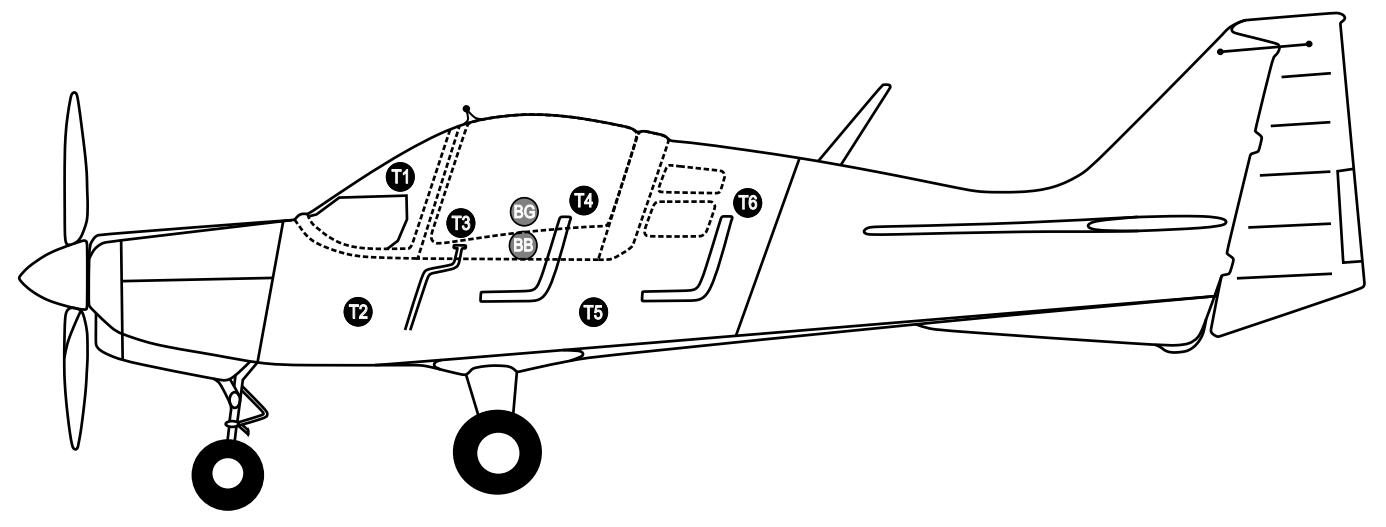

Fig. 3. Placing of the temperature and thermal comfort measurement instrumentation inside the Scottish Aviation Bulldog aircraft during the experiment. Black markers indicate the positions of dray air temperature $(T 1-T 6)$ probes while gray markers show the position of the black globe (BG) and Botsball (BB) thermometer.

All temperature measurements were logged using a SWEMA TC301 temperature measurement instrument utilizing $\mathrm{K}$ type thermocouples as temperature probes. The error of measurement for the logger was specified by the manufacturer to $\pm 0.1 \%$ or $\pm 0.7^{\circ} \mathrm{C}$ and for the thermocouples to $\pm 0.75 \%$ or $\pm 2.2^{\circ} \mathrm{C}$. Globe temperature was measured using two standard $150 \mathrm{~mm}$ black globe thermometers placed inside the cockpit, on both the pilot and copilot side, slightly above pilot seat height. Wet globe temperature data were collected in a similar fashion, likewise slightly above pilot seat height but in the center of the cockpit using a Botsball thermometer. The measured 
data from the black globe thermometers were averaged, and wet globe temperature (Botsball) $T_{w g}$ was converted to WBGT as presented in Eq. (28) according to Onkaram [35].

$$
W B G T=1.044 T_{w g}-0.187
$$

\section{Results}

\subsection{Compartment and comfort model validation}

Dry air temperature was measured at different places inside the cockpit. The sampled air temperatures (Fig. 4) show only small changes over time when the aircraft was located inside the hangar at the beginning of the measurement campaign. This changed instantly when the aircraft was pulled outside the hangar, where it was exposed to direct sun radiation. While temperatures measured at positions with direct sunlight increased rapidly, temperatures measured at more protected positions showed a moderate increase, resulting in a highly non-uniform temperature spread through the cockpit. When the aircraft after 1 hour and 30 min was placed back inside the hangar all temperatures decreased towards the temperature inside the hangar.

Ambient air temperatures, both outside and inside the hangar, and sun radiation were recorded and provided to the model as input parameters. Since the experiment was conducted ante meridiem when sun intensity was still increasing (Fig. 5 a), both radiation and outside air temperature measure- 

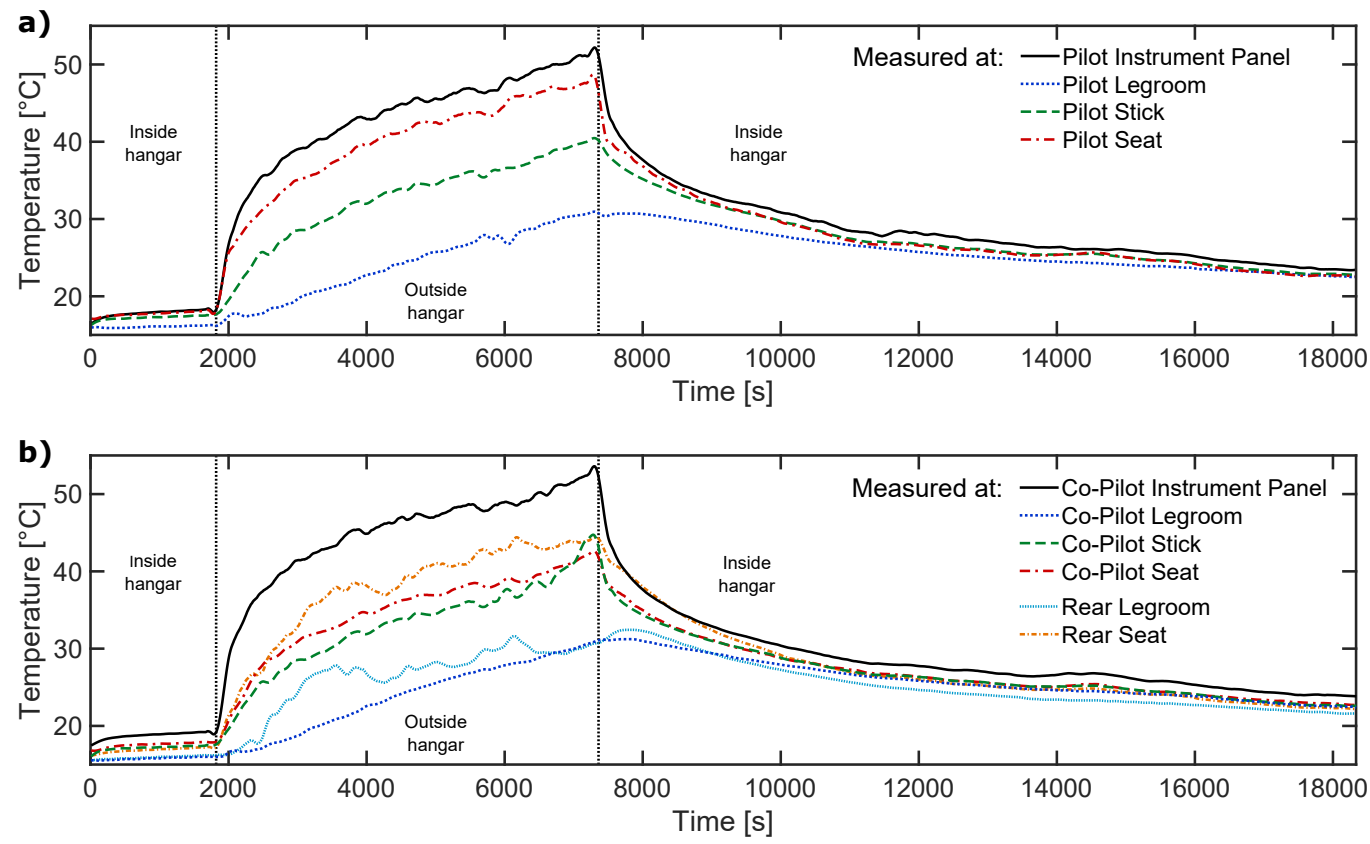

Fig. 4. Temperature profiles measured inside the cockpit at different places. The distinct increase in temperature outside the hangar is caused by sun radiation.

ments showed an upward trend. The downward directed peaks in the sun radiation measurements are caused by small clouds that masked the sun for some seconds.

For the purpose of on-ground model validation an averaged experimental cockpit air temperature (Fig. 5 a) was calculated considering all recorded cockpit temperatures. In addition, computed hood and interior temperatures, which have a significant effect on the modeled cockpit air temperature, are presented in Fig. 5 a. Beyond that, Fig. 5 b) presents an overview of the heat exchange for the cockpit interior including its radiative and convective heat fluxes. 

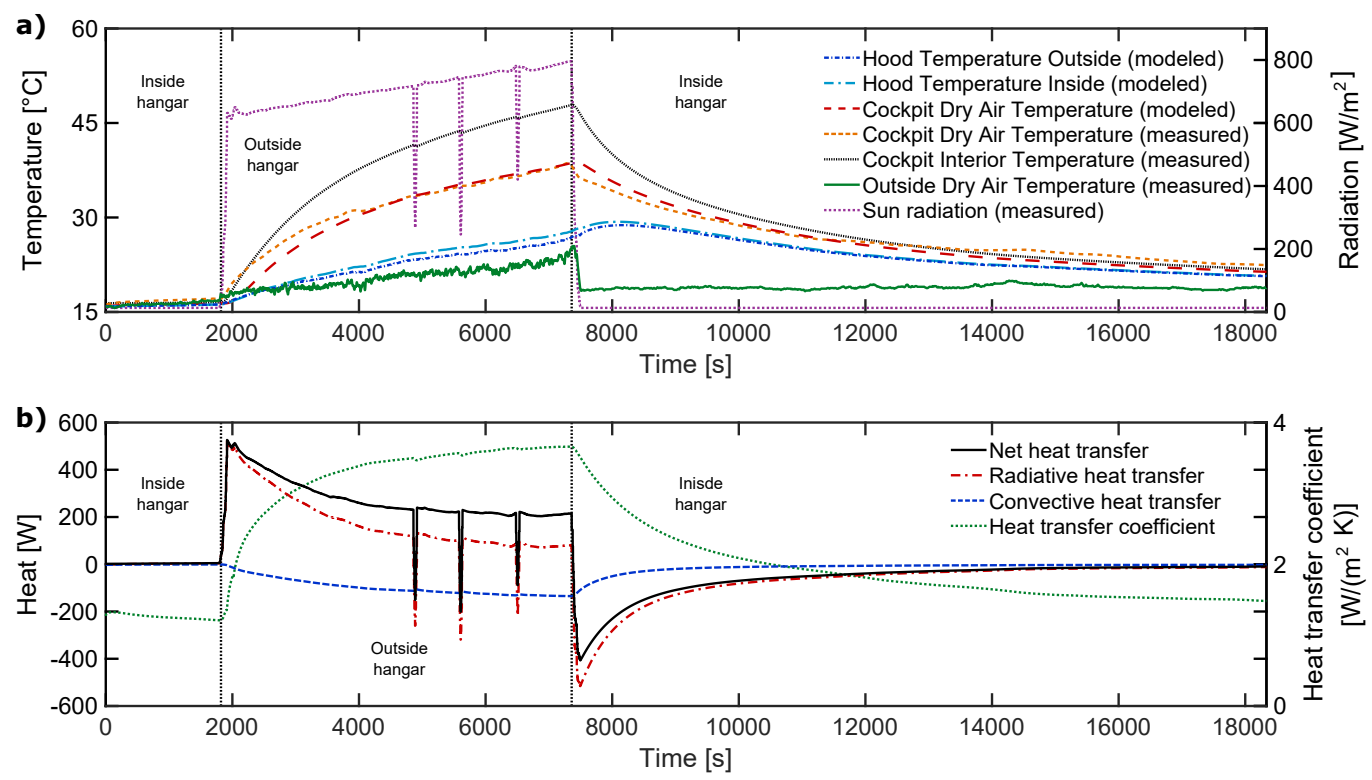

Fig. 5. a) Modeled cockpit air and hood temperatures together with sun radiation and outside air temperature serving as input data to the model. Furthermore, cockpit air temperature is compared to experimental data for validation. b) The net heat flux to and from the cockpit interior together with the radiative and convective heat transfer components and the net convective heat transfer coefficient.

Based on the environmental and cockpit air temperatures, thermal comfort was estimated. Fig. 6 presents modeled results for WBGT Eq. (3) plus its two most determining factors black globe and wet bulb temperature; two of them are validated against experimental data.

As mentioned earlier WBGT yields little useful information unless compared to a reference. Modeled WBGT was therefore set in relation to heat stress limits defined by ISO 7243 (Fig. 7 a) for an acclimatized person with light clothing (0.6 clo) at different metabolic rates. Considering piloting an aircraft as a physical stress with a low metabolic rate, it can for example be seen that modeled WBGT exceeds the maximum of $33^{\circ} \mathrm{C}$ at the end of the sun exposure 

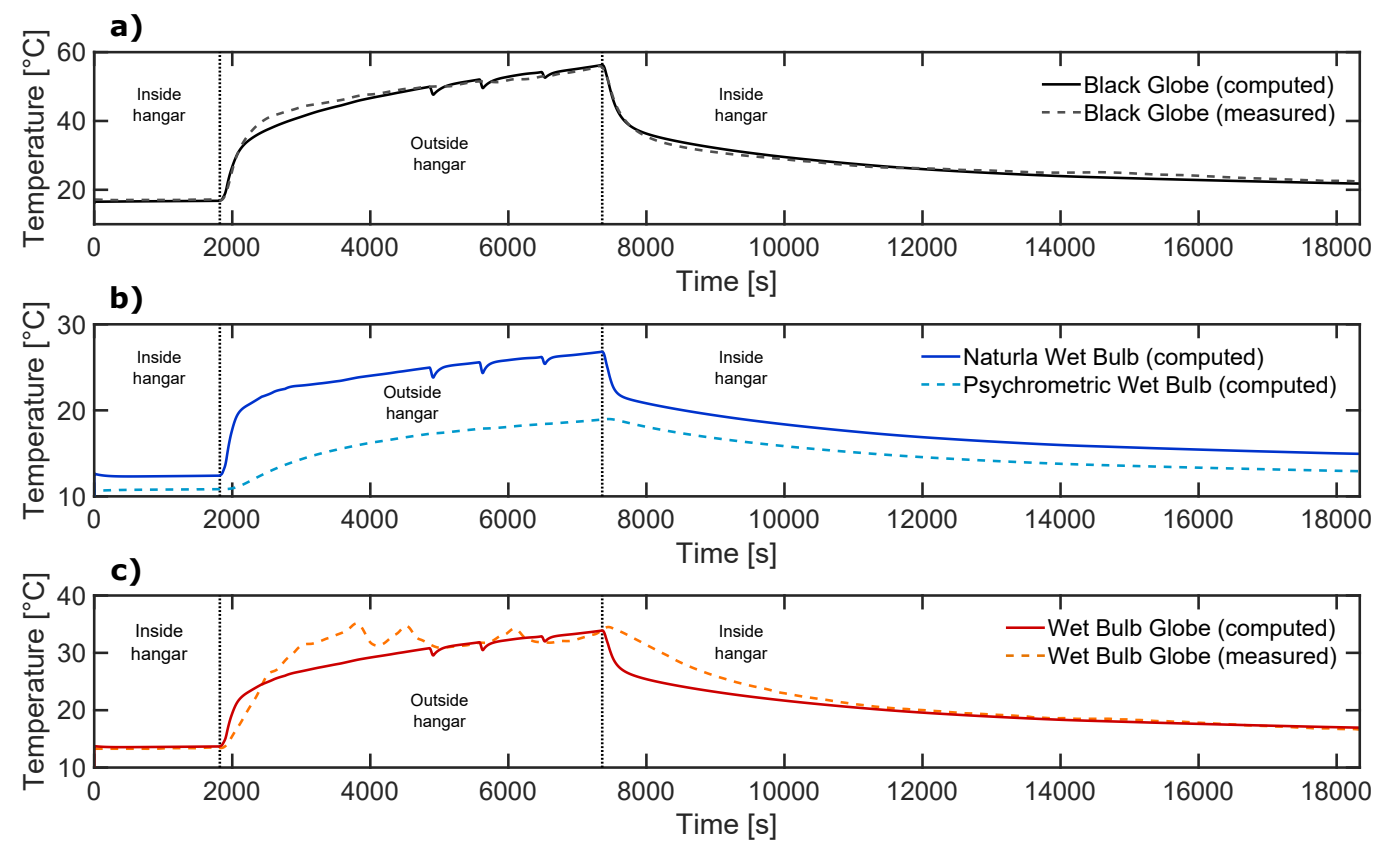

Fig. 6. Results for simulated WBGT, black globe, and wet bulb temperature. Two of them are compared to experimental data.

time, indicating a high risk for heat related illnesses.

While ISO 7423 restrictions call for attention to be paied to physiological performance limits of a human, Hancock's [28] psychological borders (Fig. 7 b) focus on the loss of mental performance capabilities (section 2). Applying these cognitive limits to the modeled WBGT results (shown above) it can be observed that, to the time the cockpit air temperature reaches its maximum, a human sitting inside the cockpit would already have lost both vigilance and dual-task performance. It is also worth mentioning that the mental threshold limits take the exposure time of the occupants into account, while this time dependence is not reflected in Fig. 7 a). 

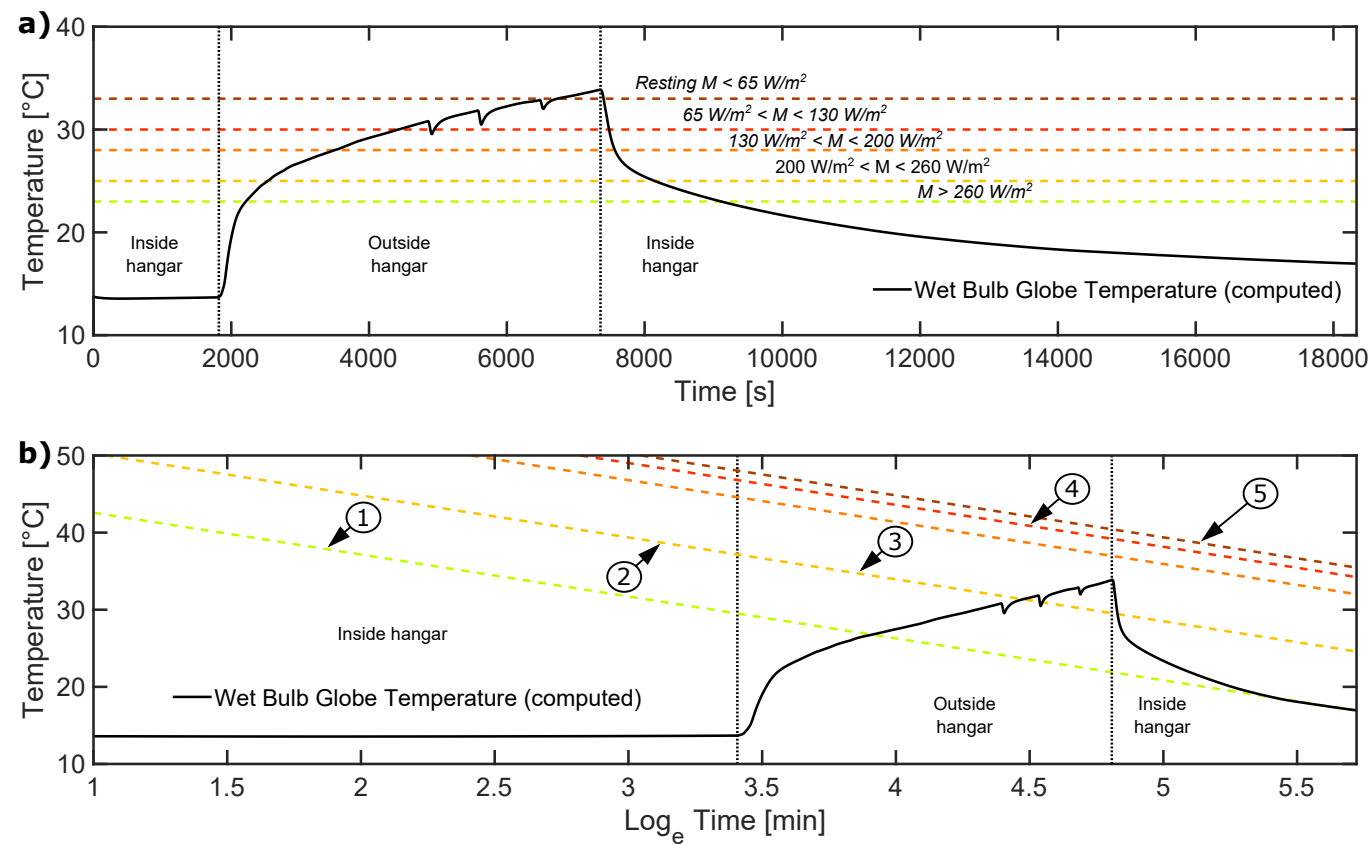

Fig. 7. a) Sets modeled WBGT of an acclimatized person into perspective with physiological thresholds allowing a maximum rectal temperature of $38^{\circ} \mathrm{C}$ at the respective metabolic rate (M). b) Sets the same WBGT results in relation to psychological performance limits depending on exposure time indicating a loss of: 1) vigilance performance, 2) dual-task performance, 3) tracking performance, and 4) simple mental performances. Limit 5) indicates exceeding of a person's physiological tolerance.

Based on the same thermal comfort model, output results for FITS (Fig. 8 a) together with flight feasibility limits suggested by Stibley and Nunneley [29] are presented. They indicate indirectly both a mental and a physical decrease in crew performance with increasing air temperature. For the same input data as provided to WBGT, computed FITS shows that flight conditions at the maximum cockpit air temperature cause a caution warning to the flight crew, meaning that subtle physiological and psychological impairment can occur during longer exposure times.

Aircraft occupants with high clothing insulation or wearing a vapor-barrier 

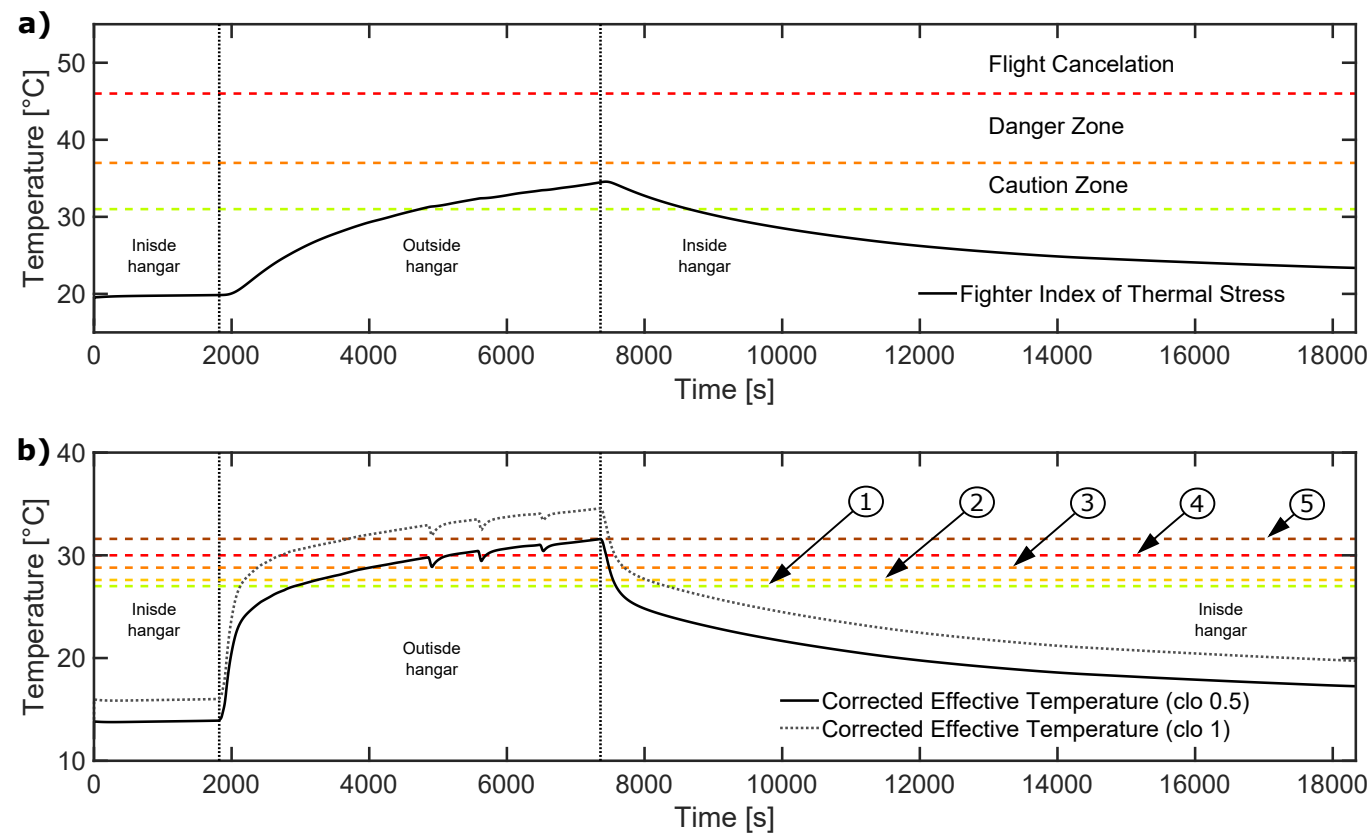

Fig. 8. a) Modeled FITS together with recommended flight operational limits valid for a fighter pilot with 1.5-2 clo in hot environments. b) CET in relation to Tanaka 36. Occupational exposure limits using Relative Metabolic Rate (RMR) as a measure of work load as proposed by the Japan Society for Occupational Health [37. 1) Heavy workload with $\mathrm{RMR}=5$, 2) Moderate workload with $\mathrm{RMR}=4,3$ ) Modest workload with $\mathrm{RMR}=3$, 4) Light workload with $\mathrm{RMR}=2$, and 5) Very light workload with $\mathrm{RMR}=1$.

overall (e.g. a sea survival suit) experience thermal discomfort more distinctly. Modeled CET (Fig. 8 b) is shifted up by $2-3^{\circ} \mathrm{C}$ if clothing insulation is increased. The shift also implies that the CET heat stress limits suggested by 37] and Tanaka [36] are exceeded faster and more explicitly.

The different assessments of thermal comfort experienced by men and women under the same thermal conditions are demonstrated by modeled PMV (Fig.9]a) showing an overall lower thermal comfort evaluation by females. This in turn results in a higher female PPD (Fig. 9 b) when the aircraft is inside the hangar, whereas comfort would be sensed less distracting, compared to 

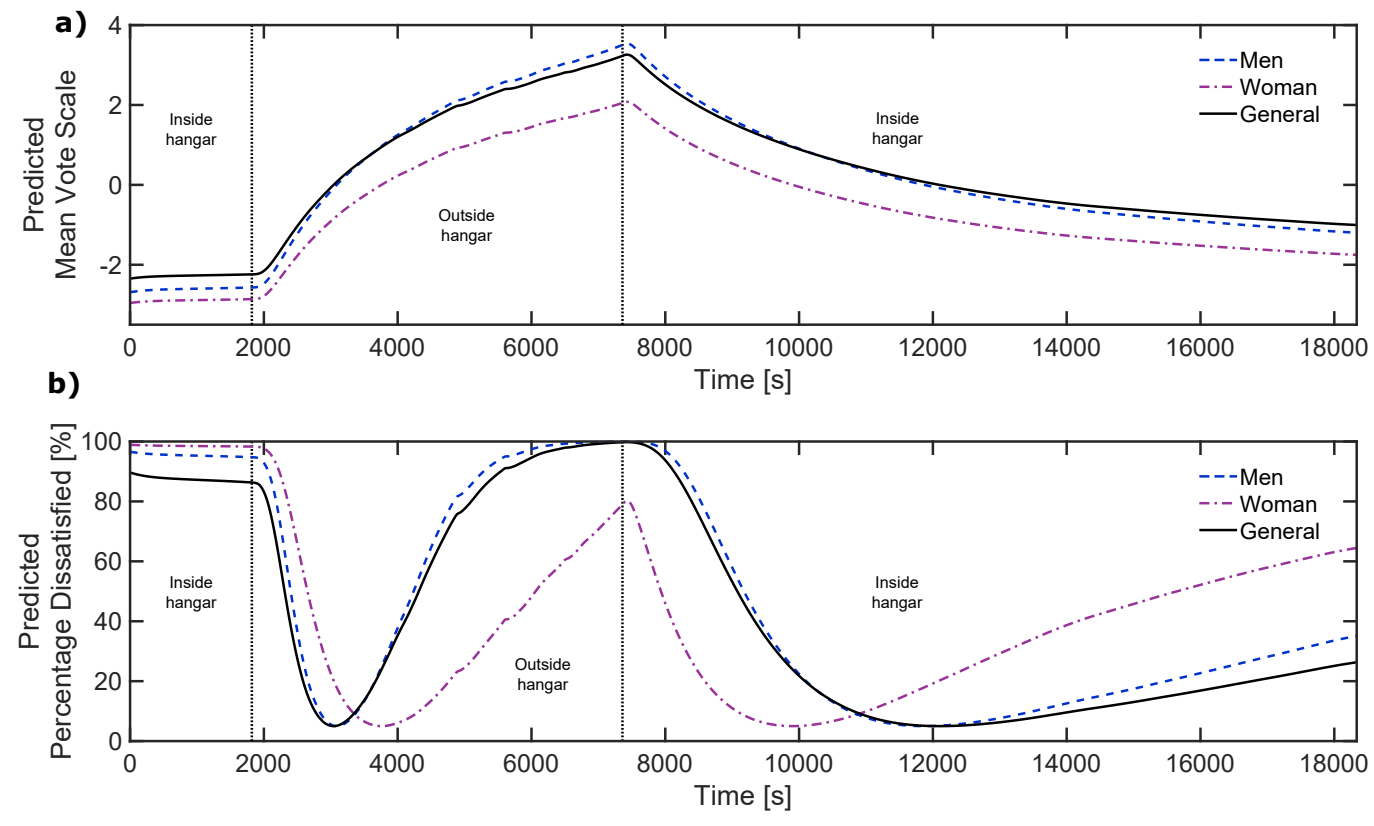

Fig. 9. a) Simulated PMV where -3 indicate a cold, -2 a cool, -1 a slightly cold, 0 a neutral, 1 a slightly warm, 2 a warm, and 3 a hot sensation of thermal environment in which the aircraft occupants are situated at a given moment. b) The occupants' PPD with their present thermal condition.

men, when cockpit air temperature is at its maximum. However, both men and women would feel thermally uncomfortable most of the time since the PPD values on average lie above 10\%, which ASHRAE 55 recommends as acceptable.

\section{Discussion}

In this study a combined model for simulation of compartment climate and assessment of thermal comfort was presented. The compartment model uses input data provided by experiments or atmosphere models, and includes all parts inside the cockpit such as seats, panels, and instruments. Its main 
task is to model the heat exchange processes within the cockpit correctly and provide reliable thermal data to its sub-models. To test and validate the model an experiment was elaborated where an aircraft was exposed to sudden large environmental changes. To obtain comparative data a measurement campaign was conducted in which dray air, black globe, and Botsball temperature inside a cockpit were collected.

Exposing the aircraft to direct sun radiation (Fig. 5 a) increases both interior and cockpit air temperatures significantly. A comparison between the computed and the experimentally determined mean cockpit air temperature (Fig. 5 a) evidences, with an average error over time of $\pm 0.6^{\circ} \mathrm{C}$, close agreement between model and experiment. At the beginning, radiation to and from the interior (Fig. 5 b) is the dominating factor of the heat-up process; later it begins to decay. The decay is on the one hand caused by the increased temperature of the inner surface of the cockpit hood (Fig. 5 a) to which the interior radiates, and on the other hand due to rising natural convection. The driving force behind the increasing convective heat transfer is the increasing difference between the interior and cockpit air temperature (Fig. 5 a) during the sun exposure period. This, in turn, increases the motion of the cockpit air, which affects the convective heat transfer coefficient (Fig. 5 b). The increased convective energy transfer from the interior to the cockpit air is also the explanation for the faster decay during sun exposure of the net heat transfer while radiation remains high. 
Withdrawing the sun as the major energy source lets the strongly heated interior immediately emit a large amount of its heat to the hood, which conducts the majority of the energy out of the cockpit, and the outer surface of the hood radiates to its cooler surroundings. Because of the almost stagnated air flow inside the closed hangar convection is limited, leading to the drawn-out decay of the cockpit air temperature (Fig. 5 a).

The estimation of thermal comfort and the related temperatures basically follow a similar modeling approach to that presented for the cockpit temperature. For both black globe and wet bulb temperature a heat balance was established considering the time-varying radiative and convective heat transfer processes. Since mass changes at the wet bulb thermometer due to evaporation and moistening a mass balance in analogy to Liljegreen [26] was used to model the water vapor flux.

Computed black globe temperature (Fig. 6) shows, with an agreement of $\pm 0.7^{\circ} \mathrm{C}$, a satisfying conformity with measurements. A match to a good degree, with an average error of $\pm 0.9^{\circ} \mathrm{C}$, was also obtained between simulated and experimental WBGT. From this it also follows that both psychometric and natural wet bulb temperatures move within a performable range. On the basis of the presented results it can be concluded that WBGT modeling can be considered to be validated.

The capability to model black globe, wet bulb, and dry air temperature 
offers the possibility to analyze and optimize thermal comfort by utilizing a large number of different thermal comfort indices (Fig. 7, Fig. 8, Fig. 9), which make use of these three temperatures. Combining the computed indices with different limits (Fig. 7, Fig. 8) enables basic thermal comfort assessment on occupants seated in the cockpit. Fig. 7 b) also shows a possible way to overcome a limitation of many commonly used heat stress indices indicating primarily instantaneous thermal comfort without considering prodromal physiological and mental discomfort of the occupant. Hancock's [28] heat stress limits support transient simulations that increase the predictive value when occupants are exposed for a longer period.

Furthermore, modeling thermal comfort indices facilitates predictions of possible thermally induced risks that may affect a pilot's physiological and psychological performance and thereby flight safety. In addition, aircraft subsystems like the ECS can benefit from thermal comfort simulations, which can enable improved automatized air conditioning, especially in situations were manual thermal comfort adjustments are less prioritized or not possible.

With its minimum of complexity the 1D model provides fast and reliable comfort estimation. Moreover, the generic design of the model and its high flexibility make fast adaptations to potentially more comprehensive heat transfer or equipment situations readily possible, thereby offering a broad range of applicability for different kinds of studies related to thermal comfort. The model can thus be used for example as a conceptual design tool in automotive- 
and aviation-related industries or as decision support for instructors and rescue services. The model also opens up for multidisciplinary studies where the causes and consequences of thermal comfort can be researched from either a more global or an individual perspective.

\section{Conclusion}

In this study a method enabling the user to predict and evaluate thermal comfort inside a generic aircraft cockpit was presented. Through the possibility to compute heat stress indices such as WBGT, CET, FITS, PMV, and other fundamental parameters, risk assessment and thermal comfort optimizations can be quickly realized. The model was validated on ground and showed good agreement with experimental data.

\section{Acknowledgments}

The author acknowledge Malmens Veteranflygklubb (MVFK) as well as Linköpings Flygklubb (LFK) for the making their aircraft and related infrastructure available.

\section{Author contributions}

R.G and J.S. planned and directed the study. R.G and J.S. contributed to the design of the model and the computational framework. J.S. performed the 
experiments, carried out the implementation of the program and performed the numerical simulations. R.G and J.S. analyzed and verified the numerical and experimental data. J.S. wrote the manuscript in consultation with R.G who supervised the project.

\section{Competing financial interests}

This research did not receive any specific grant from funding agencies in the public, commercial, or not-for-profit sectors. Hence the authors can declare no conflict of competing financial interests.

\section{References}

\section{References}

[1] Sarah A. Nunneley, Richard F. Stribley, and J. R. Allan. Heat stress in front and rear cockpits of F-4 aircraft. Aviation Space and Environmental Medicine, 52(5):287-290, 1981.

[2] P. K. Jain and K. S. Soodan. Heat stress in fighter-upgrade aircraft. Indian Journal of Aerospace Medicine, 46(1):1-6, 2002.

[3] Froom Paul, Yeheskia Cainel, Lgal Shochat, and Joseph Ribak. Heat stress and helicopter pilot errors. Journal of Occupational and Environmental Medicine, 35(7):720-724, 1993. 
[4] Stijn Van Craenendonck, Leen Lauriks, Cedric Vuye, and Jarl Kampen. A review of human thermal comfort experiments in controlled and semicontrolled environments. Renewable and Sustainable Energy Reviews, 82(3):3365-3378, 2018.

[5] United States Mid-Century Strategy for Deep Decarbonization. The White House, November 2016.

[6] T. Altenburg, C. Assmann, and Eds. Green Industrial Policy: Concept, Policies, Country Experiences. German Development Institute, December 2017.

[7] J. A. Rosero, J. A. Ortega, E. Aldabas, and L. Romeral. Moving towards a more electric aircraft. IEEE Aerospace and Electronic Systems Magazine, 22(3):3-9, 2007.

[8] Aircraft Electrical Propulsion - The Next Chapter of Aviation? Roland Berger LTD, September 2017.

[9] Jeffrey Freeman, Philip Osterkamp, Michael Green, Andrew Gibson, and Schiltgen Benjamin. Challenges and opportunities for electric aircraft thermal management. Aircraft Engineering and Aerospace: An International Journal, 86(6):519-524, 2014.

[10] K. McCarthy, E. Walters, A. Heltzel, R. Elangovan, G. Roe, W. Vannice, C. Schemm, J. Dalton, S. Iden, P. Lamm, C. Miller, and A. Susainathan. 
Dynamic Thermal Management System Modeling of a More Electric Aircraft. In SAE Power Systems Conference, 2008.

[11] Standard. ASHARE Standard 55 - Thermal Environmental Conditions for Human Occupancy. Technical report, American Society of Heating, Refrigerating and Air-Conditioning Engineers, Atlanta, US, 2013.

[12] Sami Karjalainen. Gender differences in thermal comfort and use of thermostats in everyday thermal environments. Building and Environment, 42(4):1594-1603, 2007.

[13] L. Schellen, W.D. Van Marken Lichtenbelt, M.G.L.C. Loomans, J. Toftum, and M.H. De Wit. Differences between young adults and elderly in thermal comfort, productivity, and thermal physiology in response to a moderate temperature drift and a steady-state condition. Indoor Air, 20(4):273-283, 2010.

[14] I. Knez and S. Thorsson. Influences of culture and environmental attitude on thermal, emotional and perceptual evaluations of a public square. International Journal Biometeorol, 50(5):258-268, 2006.

[15] Hilde Frevik. Impact of protective clothing on thermal and cognitive responses. PhD thesis, Norwegian University of Science and Technology, November 2010.

[16] F. C. Houghton and C.P. Yaglou. Determining equal comfort lines. 
Journal of the American Society of Heating and Ventilating Engineers, 29:165-176, 1923.

[17] P. O. Fanger. Thermal Comfort: analysis and applications in environmental engineering. PhD thesis, Copenhagen, DK, 1970.

[18] Yoram Epstein and Daniel S. Moran. Thermal Comfort and the Heat Stress Indices Heat Balance and Heat Exchange. Industrial Health, 44(3):388-398, 2006.

[19] H.M. Vernon. The Measurement of Radiant Heat in Relation to Human Comfort. Journal of Industrial Hygiene, 14:95-111, 1932.

[20] T. Bedford. The Warmth Factor in Comfort at Work. A Physiological Study of Heating and Ventilation. Number 76 in Medical Research Memorandum. Medical Research Council, 1936. London: H.M.S.O.

[21] T. Bedford. Environmental Warmth and Its Measurement. Number 17 in War Memorandum. Medical Research Council, 1940. London: H.M.S.O.

[22] Standard. ISO 7243:1989 - Hot environments - Estimation of the heat stress on working man, based on WBGT-index (wet bulb globe temperature). Technical report, International Organization for Standardization, Geneva, CH, June 1989.

[23] Vincent E. Dimiceli, Steven F. Piltz, and Steven A. Amburn. Estimation of Black Globe Temperature for Calculation of the Wet Bulb Globe 
Temperature Index. In World Congress on Engineering and Computer Science, 2011.

[24] Charles H. Hunter and C. Olivia Minyard. Estimating Wet Bulb Globe Temperature Using Standard Meteorological Measurements. Technical report, U.S. Department of Commerce, National Technical Information Service, 1999.

[25] Bruno Lemke and Tord Kjellstrom. Calculating Workplace WBGT from Meteorological Data: A Tool for Climate Change Assessment. Industrial Health, 50(4):267-278, 2012.

[26] James C. Liljegren, Richard A. Carhart, Philip Lawday, Stephen Tschopp, and Robert Sharp. Modeling the wet bulb globe temperature using standard meteorological measurements. Journal of Occupational and Environmental Hygiene, 5(10):645-655, 2008.

[27] Adélio R. Gaspar and Divo A. Quintela. Physical modelling of globe and natural wet bulb temperatures to predict WBGT heat stress index in outdoor environments. International Journal of Biometeorology, 53(3):221-230, 2009.

[28] P.A. Hancock and Ioannis Vasmatzidis. Human occupational and performance limits under stress: the thermal environment as a prototypical example. Ergonomics, 41(8):1169-1191, 2017. 
[29] Richard F. Stibley and Sarah A. Nunneley. Fighter Index of Thermal Stress: Development of Interim Guidance for Hot-Weather USAF Operations. Technical report, USAF School of Aerospace Medicine, 1978.

[30] ASHRAE Handbook Fundamentals. American Society of Heating, Refrigerating, and Air-Conditioning Engineers, 1 edition, 1993.

[31] Standard. ISO 2533:1975 - Standard Atmosphere. Technical report, International Organization for Standardization, Geneva, CH, May 1975.

[32] Mudambi R. Ananthasayanam and Roddam Narasimha. A proposed international tropical reference atmosphere up to $80 \mathrm{~km}$. Advances in Space Research, 5(7):145-154, 1985.

[33] Joseph C. Zuppardo. Graphical Comparison of U.S. Standrd Atmosphere and Military Standard Climatic Extremes. Technical report, Aeronautical Systems Center, February 1993.

[34] Arden L. Buck. New Equations for Computing Vapor Pressure and Enhancement Factor. Journal of Applied Meteorology, 20(12):1527-1532, 1981.

[35] B. Onkarm, L.A. Stroschein, and R.F. Goldman. Three Instruments for Assessment of WBGT and a Comparison with WBGT (Botsball). American Industrial Hygiene Association Journal, 41(9):634-641, 1980.

[36] Masatoshi Tanaka. Heat Stress Standard for Hot Work Environments in Japan. Industrial Health, 45(1):85-90, 2007. 
[37] The Japan Society for Occupational Health. Recommendation of Occupational Exposure Limits (20172018). Journal of Occupational Health, 59(5):436-469, 2017. 